\title{
Original article (short paper) \\ "Athletic Identity Measurement Scale": Translation, Adaptation and Validation for Brazil
}

\author{
Walan Robert da Silva \\ Universidade do Estado de Santa Catarina, Florianópolis, SC, Brasil \\ Elisa Pinheiro Ferrari \\ Thiago Emannuel Medeiros \\ Universidade do Estado de Santa Catarina, Florianópolis, SC, Brasil \\ Kamyla Thais Dias de Freitas \\ Universidade do Estado de Santa Catarina, Florianópolis, SC, Brasil \\ Claudio Marcelo Tkac \\ Pontificia Universidade Católica do Paraná, Curitiba, PR, Brasil \\ Fernando Luiz Cardoso \\ Universidade do Estado de Santa Catarina, Florianópolis, SC, Brasil
}

\begin{abstract}
The aim of this study was to translate, adapt and validate the version of the Athletic Identity Measurement Scale (AIMS) for Brazilian Portuguese. The methodological procedures were conducted according to international recommendations: translation, back-translation, review by a board of experts, empirical fieldwork testing and inferential statistical analyses. The psychometric properties were evaluated by applying the translated scale to 127 university students. Reproducibility was assessed through stability and homogeneity assessment. Validity was assessed by comparing the scores obtained from the athletes and university students. The results showed good internal consistency $(\alpha=0.78)$, when item 3 was removed and the Cronbach's alpha value increased to 0.82 . Through factor analysis, we verified that the items had loadings in two domains. Intra-class correlation coefficient for test and retest was 0.91 . Comparison between athletes and university students showed good discriminant validity. According the cultural adaptation process the adapted instrument has excellent psychometric properties and is reliable for the Brazilian culture.
\end{abstract}

Keywords: translating, reproducibility of results, athletic performance.

\section{Introduction}

Identity study has been intriguing psychologists for over a century, and although it has many definitions (Brewer, Raalte \& Linder, 1993; Lamont-Mills \& Christensen, 2006; Wiechman \& William, 1997), practically all of them share the core assumption that the subject's identity acts as one of the main determinants of internal behavior. According to Cieslak (2004), individuals define their identity through social living. Thus, athlete-subjects will define their identity through experienced sporting interactions (Wiechman \& Williams, 1997) and this mutual interaction between the athlete and the sporting situation called the attention of the scientific community for the study of athletic identity (AI).

AI may be understood as how athlete-subjects, who practice a sport in a systematic and professional way, build the notion of themselves, in relation to the emotions of their interpersonal living and their interactions resulting from sporting practices (Brewer et al., 1993). Studies regarding this subject have shown that this is a social construct, clearly influenced by friends, family, colleagues, trainers, and the sporting context. This interaction allows the athletes to form identities that enable them, to distinguish themselves from others and, simultaneously giving them a feeling of belonging to a defined group (Anderson \& Coleman, 2008). In addition, influencing experiences, relationships and their involvement with the sporting activity (Cornelius, 1995; Lau, Cheung \& Randsdell, 2007; Lau, Fox \& Cheung, 2004, Anderson, Mâsse, Zhang, Coleman\& Chang, 2009).

With that in mind, many authors have been trying to develop an AI concept since the 90s (Brewer et al., 1993; Horton \& Mack, 2000; Hurst, Hale, Smith \& Collins, 2000; Martin, Mushet \& Smith, 1995; Smith, Hale \& Collins, 1998). Accordingly, Brewer et al. (1993) proposed an instrument for its evaluation, the Athletic Identity Measurement Scale (AIMS), which many national and international studies have broadly used (Martin et al., 1995; Murphy, Petitpas \& Brewer, 1996; Grove, Lavallee \& Gordon, 1997; Martin, Eklund \& Mushett,1997; Tasiemski, Kennedy, Gardner \& Blaikley, 2004; Grove, Fish \& Eklund, 2004; Lamont-Mills \&Christensen, 2006; Brewer, Cornelius, Stephan \& Van Raalte,2010), including its translation and adaptation to many countries (Harris \& Watson, 2011; Schmid \& Seiler, 2003; Hale, James \& 
Stambulova, 1999; Hin \&Anderson, 2008) to evaluate AI in different sports.

According to previous studies, we did not find the existence of a national instrument to evaluate $\mathrm{AI}$, as well as the translation, adaptation and validation of the AIMS for the Brazilian population. The validation of the instrument for Brazil will bring another tool to help in assessing the identity of our current athletes, as well as to examine the athletic identity of young people interested in starting a life in sports. Therefore, the objective of this study was to translate, adapt and validate the version of the AIMS for Brazilian Portuguese that have been used informally inside the country.

\section{Methods}

AIMS is an instrument developed by Brewer et al. (1993) aiming to evaluate the levels of AI. It is composed of 7 items, subdivided in to three subscales or dimensions: social identity (items 1,2 and 3), exclusivity (items 4,5 ) and negative affectivity (items 6,7 ), with a 7-point Likert scale as answer format, varying from 1 (completely disagree) to 7 (agree), resulting in a total AI score, with a sum of the answers given by the participant, 7 points being the minimum score and 49 the highest. Higher score means stronger AI".

For the process of translation and empirical and analytical testing of the instrument, the methodological steps presented in Figure 1 and described in the topics below were conducted. We accepted the theoretical construct built by the authors, with focus on translation and empirical and analytical testing of the instrument in Portuguese.

\section{Translation and cross-cultural adaptation}

To ensure the quality of the adaptation, this study followed the essential steps recommended by specialized literature (Hutchinson, Bentzen \& Konig-Zanhn, 1996; Guillemin, Bombardier \& Beaton 1993; Alexandre \& Guirardello, 2002). These steps are described below.

First two independent sworn translators, whose first language was Portuguese, translated the AIMS. Therefore, we obtained two different versions of the scale: T1 and T2. After this stage, there was a meeting with both translators and the principal investigators, which defined a consensual $\mathrm{T} 1+2$ version in Brazilian Portuguese.

The $\mathrm{T} 1+2$ version was handed to a third sworn translator, whose first language was English, and who was fluent in Portuguese and did not know the original instrument. The questionnaire T1 +2 was translated to English (back-translation). The original version and the back-translation were then compared in a meeting between the last translator and the principal investigator, who established a consensual Portuguese version named T3.

\section{Cultural adaptation}

After the translation, the clarity and reliability of $\mathrm{T} 3$ were tested on 90 athletes selected by convenience taking into consideration the inclusion criteria, training in a systematic way, participating in high performance competitions, training in a systematic way at least for 1 year and training at least 3 times a week from the cities of Curitiba and Guarapuava, Paraná, of whom 74 were men and 16 were women, distributed across the following sports: 43 soccer, 34 swimming and 13 indoor soccer athletes. They answered both versions, $\mathrm{T} 3$ and $\mathrm{T} 1+2$, to assess the level of agreement between versions and the clarity of all questions in both versions.

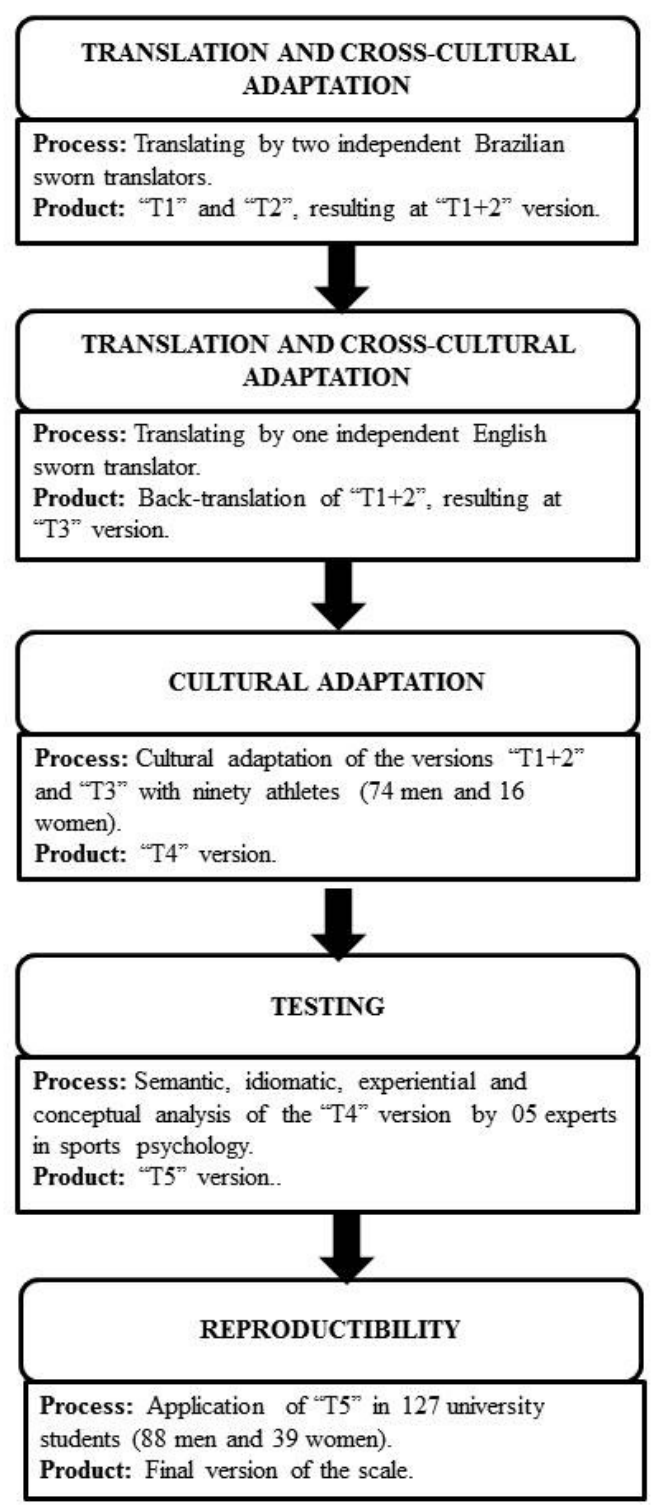

Figure 1. Methodological steps for translating, adapting and validating the AIMS.

In the first round, 45 research subjects received the T3 version of the instrument, and the other 45 received the $\mathrm{T} 1+2$ version. After an interval between 14 and 21 days, the scale was re-applied, with the subjects who answered $\mathrm{T} 1+2$ answering $\mathrm{T} 3$ and, conversely, the opposite also happened.

The respondents were instructed to answer the instrument normally, in addition to rating each item with a grade that 
represented its level of clarity, with " 0 " for very unclear and "10" for very clear, and giving suggestions for relevant changes. The level of clarity of the items was obtained through their mean grades, from the rating parameters proposed by Melo (2002): from 0 to 4, the question is confusing; from 5 to 7, the question is unclear; and from 8 to 10 , the question is very clear. In the case of scores under 8 , the corresponding items were reassessed by the researchers according to comments and suggestions by participants during the assessment. At the end of this step, we developed a new version of the instrument, version T4. We collected individual data, such as age, gender and sport practiced, along with the questionnaire.

For the last empirical procedure, the T4 version was sent to a board with five experts in physical education and five experts in sports psychology, who assessed equivalence in four areas: semantic, idiomatic, experiential and conceptual. After this assessment, the board identified and debated discrepancies. A report was produced and a final version was validated and approved, version T5.

In order to verify the scale's reproducibility and the validity of the construct proposed by the authors of the final version (T5), a second group of participants, selected by convenience taking into consideration the criteria, not being a professional athlete, composed of 127 university students from the physical education course -88 men and 39 women, with a average age of $21.6( \pm 3.35)$ answered the final version of the instrument. The protocol for scale application was similar to the one used in the first gathering and the interval for reapplying the test was 14 days.

Reproducibility was verified through test and retest of the instrument, and discriminant validity was verified by comparing score means obtained from athletes and non-athletes, physical education students, for each item that composes the scale.

\section{Statistical analysis}

Data was categorized with Microsoft Excel $\AA^{\circledR}$ and analyzed using the Statistical Package for the Social Sciences (SPSS) ${ }^{\circledR}$, version 20.0. We used descriptive statistics to describe participants. The analysis of the data distribution was verified through performing Kolmogorov-Smirnov normality, test Cronbach's Alpha was used to verify internal consistency, considering as minimum acceptable value 0.70 (Oviedo \& Campo-Arias, 2005).

We assessed the construct's validity through exploratory factor analysis with Varimax rotation, which identifies common components in a large number of variables, a minimum acceptable load 0.50 was considered (Hair, Black, Babin, Anderson \& Tatham, 2006).

This assessment makes it possible to determine how the scale is related to the theoretical concepts that support it. Testretest reliability was tested using the intraclass correlation coefficient, paired t-test was used to compare the averages between the test and retest, and agreement was tested through Kappa index. Reference values for this analysis were: $<0.40$, weak correlation; 0.40 to 0.60 , moderate correlation; 0.60 to 0.80 , good to substantial correlation; $>0.80$, almost perfect or very good correlation (Fayers \& Machin, 2007). The difference between results obtained from the two types of population was calculated using Student's t-test for independent samples. The level of significance adopted for all statistical tests was 5\%.

The research was conducted within the standards established by the Declaration of Helsinki and approved by the Human Research Ethics Committee, according to Resolution CNS 196/96 under the protocol number: 275.381/2013.

\section{Results}

The results present data regarding dimensionality, internal consistency, reproducibility and sensitivity of the AIMS. We evaluated 217 individuals, 90 athletes and 127 non-athletes, Physical Education students corresponding to $100 \%$ participation. Factor analysis did not confirm the three dimensions of the AIMS - social identity, exclusivity and negative affectivity as proposed by the author. As shown inTable 1, the items analyzed had loadings in only two domains, "social identity/exclusivity" and negative affectivity, with a percentage of explanation of $46.99 \%$ for the first domain and $18.45 \%$ for the second.

Table 2 shows total Cronbach's alpha values, which indicate internal consistency, and the AIMS's alpha values if the shown item were to be removed from the scale. Each item was removed from the scale to verify changes in the scale's total alpha values. However, the highest value of Cronbach's alpha was observed after the removal of item 3 .

Table 1. Exploratory factor analysis of the AIMS.

\begin{tabular}{lcc}
\hline & Factor loading \\
\hline Items of the AIMS & 1st domain & 2nd domain \\
\hline I consider myself an athlete. & 0.77 & \\
I have many goals related to sport. & 0.76 & \\
Most of my friends are athletes. & 0.56 & \\
Sport is the most important part of & 0.80 & \\
my life. & & \\
$\begin{array}{l}\text { I spend more time thinking about } \\
\text { sport than anything else. }\end{array}$ & 0.79 & \\
$\begin{array}{l}\text { I feel bad about myself when I do } \\
\text { poorly in sport. }\end{array}$ & & \\
$\begin{array}{l}\text { I would be very depressed if I were } \\
\text { injured and could not compete }\end{array}$ & & \\
$\begin{array}{l}\text { in sport. } \\
\text { Percentage of explanation }\end{array}$ & & \\
\hline
\end{tabular}

Table 2. Total value and change in total Cronbach's alpha value after the exclusion of an AIMS item.

\begin{tabular}{lc}
\hline Scale items & Changed $\boldsymbol{\alpha}$ value \\
\hline Total value of the scale & 0.78 \\
If item 01 is excluded & 0.74 \\
If item 02 is excluded & 0.72 \\
If item 03 is excluded & 0.82 \\
If item 04 is excluded & 0.75 \\
If item 05 is excluded & 0.72 \\
If item 06 is excluded & 0.79 \\
If item 07 is excluded & 0.76 \\
\hline
\end{tabular}

$\alpha$ : Cronbach's alpha. 
Table 3 shows values regarding the Kappa index, agreement percentage and the p-value of the paired t-test by performing test-retest. Furthermore, we call attention to the fact that the interclass correlation coefficient was 0.91 (data not presented).

Regarding discriminant validity in Table 4, we present the values of the comparison between scores referring to the AIMS items answered by the athletes and university students. According to presented data, athletes show higher values than university students $(p<0.05)$, showing that the instrument can discriminate the aforementioned construct.

Table 3. Agreement of athletic identity measurements between test and retest of the 127 physical education students.

\begin{tabular}{lccc}
\hline Scale items & Kappa & $\mathbf{\% A}$ & p-value \\
\hline I consider myself an athlete. & 0.67 & $83.0 \%$ & 0.001 \\
I have many goals related to sport. & 0.69 & $84.0 \%$ & 0.001 \\
Most of my friends are athletes. & 0.61 & $85.0 \%$ & 0.001 \\
$\begin{array}{l}\text { Sport is the most important part } \\
\text { of my life. }\end{array}$ & 0.60 & $82.0 \%$ & 0.001 \\
$\begin{array}{l}\text { I spend more time thinking about } \\
\text { sport than anything else. }\end{array}$ & 0.57 & $80.0 \%$ & 0.028 \\
$\begin{array}{l}\text { I feel bad about myself when I do } \\
\text { poorly in sport. }\end{array}$ & 0.60 & $80.0 \%$ & 0.001 \\
$\begin{array}{l}\text { I would be very depressed if I } \\
\text { were injured and could not com- } \\
\text { pete in sport. }\end{array}$ & 0.60 & $76.0 \%$ & 0.001 \\
\hline
\end{tabular}

$\%$ A: percentage of agreement. p- value of the test Kappa.

Table 4. Comparison between athletes and university students, according to the AIMS items.

\begin{tabular}{lcccc}
\hline AIMS items & $\begin{array}{c}\text { Athlete } \\
\text { Mean (SD) } \\
(\mathbf{n}=\mathbf{9 0})\end{array}$ & $\begin{array}{c}\text { Non-athlete } \\
\text { Mean (SD) } \\
(\mathbf{n = 1 2 7 )}\end{array}$ & T & p-value \\
\hline $\begin{array}{l}\text { I consider myself } \\
\text { an athlete. }\end{array}$ & $6.38(0.97)$ & $3.49(2.15)$ & -11.92 & 0.001 \\
$\begin{array}{l}\text { I have many goals } \\
\text { related to sport. }\end{array}$ & $6.17(1.24)$ & $4.54(2.26)$ & -6.22 & 0.001 \\
$\begin{array}{l}\text { Most of my friends } \\
\text { are athletes. }\end{array}$ & $5.54(1.42)$ & $3.00(1.59)$ & -12.13 & 0.001 \\
$\begin{array}{l}\text { Sport is the most } \\
\text { important part of } \\
\text { my life. }\end{array}$ & $5.94(1.34)$ & $4.11(5.10)$ & -7.28 & 0.001 \\
$\begin{array}{l}\text { I spend more time } \\
\text { thinking about sport } \\
\text { than anything else. }\end{array}$ & $5.48(1.39)$ & $3.74(2.18)$ & -6.66 & 0.001 \\
$\begin{array}{l}\text { I feel bad about } \\
\text { myself when I do } \\
\text { poorly in sport. }\end{array}$ & $6.20(1.27)$ & $4.75(2.10)$ & -5.83 & 0.001 \\
$\begin{array}{l}\text { I would be very } \\
\text { depressed if I were } \\
\text { injured and could } \\
\text { not compete in } \\
\text { sport. }\end{array}$ & $6.24(1.44)$ & $5.17(2.25)$ & -4.00 & 0.001 \\
$\begin{array}{l}\text { Total identity } \\
\text { SD: }\end{array}$ & $41.95(5.90)$ & $28.78(11.80)$ & -9.73 & 0.001 \\
\hline
\end{tabular}

SD: standard deviation; T: Student's t-test value.

\section{Discussion}

Cross-cultural adaptation is a necessary process when using instruments that were originally built in other languages and contexts, especially when it comes to psychological aspects and the cultural diversity of humans. After performing the steps recommended in the literature (Hutchinson et al., 1996; Guillemin et al., 1993; Alexandre \& Guirardello, 2002), we obtained a Brazilian Portuguese version of the AIMS that was properly translated and adjusted to the local context. The availability of this instrument may encourage its use in studies regarding the relationship between AI and the behavior of athletes and sports practitioners.

The results obtained in the validation process of the AIMSBrazil showed that the items referring to AI's assessment have sufficient validity and reliability to be used in other studies on the subject in Brazil. All of the seven items that compose the scale have factor loadings that justify their place in the scale, according to previously established criteria (Oviedo \& Campo-Arias, 2005). The validated AIMS-Brazil met Likert's assumptions with acceptable Cronbach's alpha values, confirming a high internal consistency in the scale. Other studies that tested psychometric characteristics of the AIMS also found the internal consistency acceptable to high (Hale et al., 1999; Hin \& Anderseon, 2008; Schmid \& Seiler, 2003). Despite small changes in the total value of Cronbach's alpha, when item 3 was removed the Cronbach's alpha value increased to 0.82 , suggesting to the authors that the item 3 was not important for the scale, and its presence was not necessary in this context.

In terms of dimensionality, the AIMS-Brazil items had loadings in only two different factors, disproving the tri-dimensionality proposed by the authors, which may suggest isomorphism problems among the items created to represent each dimension in this population. Unfortunately, we did not find references to the dimensionality testing originally proposed in the AIMS in literature, which did not allow a comparison between results.

The instrument's reproducibility through the test-retest procedure was observed through Kappa coefficient and t-test for paired samples. In general, all items presented Kappa coefficients over 0.05 , representing percentages of over $70.0 \%$ of answer agreement between test and retest. These values confirmed the investigation conducted by Schmid and Seiler (2003), which found high Kappa coefficient values in the AIMS validation for the German population. Furthermore, the means of the scores obtained in the first application and in the second do not show significant differences, showing that the items of the scale, as well as the instrument in general, offer good reliability, enabling us to assume a stability of the scale over time.

Another aspect observed by this study is discriminant validity. When we compared athletes and non-athletes differences about the AI was observed, indicating the ability of the instrument to discriminate between athletes and university students in all items, which presented significant differences among the average scores of answers given by both types of participants. This indicates that athletes have higher AI than other individuals, in this case, university students. This has also been highlighted in other international studies, which describe AI as a predictor 
of sporting orientation and participation (Lau et al., 2007; Lau et al., 2004; Anderson et al., 2009).

As the limitation of this study highlights, the lack of comparison between athletes, ex athletes and non-athletes, it doesn't allow identifying if the instrument discriminates athletic identity of these three types of people. New research on the validation of the "Athletic Identity Measurement Scale" can test the variation of "Athletic Identity" between athletes and ex-athletes in order to verify the influence of aging process on this personality trait.

\section{Conclusions}

In conclusion, the Brazilian Portuguese version of the AIMS in the seven-item composition showed good psychometric performance when examined from a sample of athletes and physical education students from two municipalities of the state of Paraná, in southern Brazil.

The instrument presented satisfactory attributes of internal consistency, test-retest reliability, and discriminant validity. It is important to highlight the fact that we could not identify, in the Brazilian context, another specific instrument that assesses AI characteristics related to sporting orientation. Therefore, this instrument's availability may favor the development and effectiveness of psychological interventions related to sports. Furthermore, we also highlight the fact that even though the scale was developed for the North American population, the results found with its application confirm its effectiveness and reliability for use among Brazilians. However, some regional and sociocultural aspects must be analyzed with greater insight in order for the scale to be as extensive as it intends. Therefore, we suggest the development of further investigations nationwide in order to answer these questions - such as the proposed tri-dimensionality - in addition to including other age groups besides the ones investigated in this study.

\section{References}

Alexandre, N.M.C.,\& Guirardello, E.de B. (2002). Adaptación cultural de instrumentos utilizados en salud ocupacional. Revista Panamericana de Salud Publica. 11(2), 109-111.

Anderson, C.B.,\&Coleman, K,J. (2008).Adaptation and validation of the athletic identity questionnaire adolescent for Use with children. Journal of Physical Activity \& Health.5(4), 539-558.

Anderson, C.B., Mâsse, L., Zhang, H., Coleman, K.J.,\& Chang, S. (2009). Contribution of athletic identity to child and adolescent physical activity. American Journal of Preventive Medicine. 37(3), 220-226.

Brewer, B., Van Raalte, J.L.,\&Linder, D.E. (1993). Athletic identity: Hercules' muscles or Achilles heel?. International Journal of Sport Psychology.24(2), 237-254.

Brewer, B., Cornelius, A.E., Stephan, Y.,\&Van Raalte, J.L. (2010). Self-protective changes in athletic identity following anterior ligament reconstruction. Psychology of Sport \& Exercise. 11(1), 1-5.

Cieslak, T.J. (2004). Describing and measuring the athletic identity construct scale development and validation. Tese de doutorado, PósGraduação em Filosofia. Universidade do Estado de Ohio, U.S. A.
Cornelius, A.E. (1995). The relationship between athletic identity, peer and faculty socialization, and college student development. Journal of College Student Development. 36(6), 560-573.

Fayers, P.,\&Machin, D. (2007).Quality of life: assessment, analysis and interpretation. (2a ed.). New York: John Wiley \& Sons.

Grove, R., Lavallee, D.,\&Gordo, S. (1997).Coping with retirement from sport: the influence of athletic identity. Journal of Applied Sport Psychology.9(2), 191-203.

Grove, J.R., Fish, M.,\& Eklund, R.C. (2004). Changes in athletic identity following team selection: Selfprotection versus self-enhancement. Journal of Applied Sport Psychology.16(1), 75-81.

Guillemim, F., Bombardier, C.,\&Beaton, D. (1993). Cross-cultural adaptation of health-related quality of life measures: literature review and proposed guidelines. Journal of Clinical Epidemiology. 46(12), 1417-32.

Hair, Jr., Black, W.C., Babin, B.J., Anderson, R.E \& Tatham, R.L. (2006). Multivariate Data Analysis. (6 ${ }^{\mathrm{a}}$ ed.). Upper Saddle River, NJ: Pearson Prentice Hall.

Hale, B.D., James, B.,\&Stambulova, N.B. (1999). Determining the dimensionality of athletic identity: A herculean cross-cultural undertaking. International Journal of Sport Psychology. 30(1), 83-100.

Harris, B.S., \&Watson, J. C. (2011). Assessing youth sport burnout: A self-determination identity theorydevelopment perspective. Journal of Clinical Sport Psychology. 5(2), 117-133.

Hin, Y.L.,\&Andersen, M.B. (2008). Athletic identity in China: Examining the AIMS in a Hong Kong sample. International Journal of sport \& Exercise Psychology. 6(2), 176-188.

Horton, R.S.,\&Mack, D.E. (2000). Athletic identity in marathon runners: Functional focus or dysfunctional commitment?. Journal of sport Behavior. 23(2), 101-119.

Hurst, R., Hale, B., Smith, D.,\&Collins, Dave (2000). Exercise dependence, social physique anxiety, and social support in experienced and inexperienced bodybuilders and weightlifters. British Journal of Sports Medicine. 34(6), 431- 435.

Hutchinson,A., Bentzen, N.,\& Konig-Zanhn, C. (1996) Crosscultural health-outcome assessment: a user's guide. The Netherlands: ERGHO; 1996.

Lamont-Mills, A., \& Christensen, S.A. (2006). Athletic identity and its relationship to sport participation levels. Journal of Science and Medicine in Sport. 9(6), 472-478.

Lau, P.W.C., Cheung, M.W.L.,\&Ransdell, L. (2007). Sport identity and sport participation: A cultural comparison between collective and individualistic societies. International Journal of Sport \& Exercise Psychology. 5(1), 66-81.

Lau, P.W.C., Fox, K.R.,\&Cheung, M.W.L. (2004). Psychosocial and socio-environmental correlates of sport identity and sport participation in secondary-age children. European Journal of Sport Science. 4(3), 1-21.

Martin, J.J., Mushett, C.A.,\&Smith, K.L. (1995) Athletic identity and sport orientation of adolescent swimmers with disabilities. Adapted Physical Activity Quarterly. 12(2), 113-123.

Martin, J.J., Eklund, R.C.,\&Mushett, C.A. (1997). Factor structure of the athletic identity measurement scale with athletes with disabilities. Adapted Physical Activity Quarterly. 14(1), 74-82.

Melo, S.I.L. (2002). Apostila do processo de validação de instrumentos de medida. Florianópolis: UDESC. 
Murphy, G.M., Petitpas, A,J., \& Brewer, B (1996). Identity foreclosure, athletic identity, and career maturity in intercollegiate athletes. Sport Psychologist. 10(3), 239-346.

Oviedo, H.C., Campo-Arias, A. (2005). Aproximación al uso del coeficiente alfa de Cronbach, Revista Colombiana de Psiquiatría. 34(4), 572-580.

Schmidt, J., \& Seiler, R. (2003) Identity in high-performance sport: Psychometric investigations with a German Language adaptation of the Athletic Identity Measurement Scale(AIMS-D). Diagnostica, 49(4), 176-183.

Smith, D., Hale, B.,\&Collin, S.D. (1998). Measurement of exercise dependence in bodybuilders. Journal of Sports Medicine and Physical Fitness. 38(1), 66-74.

Tasiemski, T., Kennedy, P., Gardner, B.P., \&Blaikley, R.A. (2004). Athletic identity and sports participation in people with spinal cord injury. Adapted Physical Activity Quarterly. 21(4), 364-378.

Wiechman, S.A., \&Williams, J. (1997). Relation of athletic identity to injury and mood disturbance. Journal of Sport Behavior. 20(2), 199-231.

\section{Authors' note}

Walan Robert da Silva and Kamyla Thais Dias de Freitas are affliated with the Graduate Program in Human Movement Sciences, State University of Santa Catarina, UDESC/ Gender Lab, Sexuality and Embodiment, LAGESC, Florianopolis- SC, Brazil.

Claudio Marcelo Tkac are affliated with the Pontifical Catholic University of Paraná, Health and Biosciences School, Graduation Course in Physical Education/ Research Group about Motor Behavior, GECOM, Curitiba-PR, Brazil.

Elisa Pinheiro Ferrari, Thiago Emannuel Medeiros, Fernando Luiz Cardoso are affliated with the Graduate Program in Human Movement Sciences, State University of Santa Catarina, UDESC/ Gender Lab, Sexuality and Embodiment, LAGESC, Florianopolis- SC, Brazil.

\section{Corresponding author:}

Elisa Pinheiro Ferrari

Rua: Paschoal Simone, 358, Coqueiros, Florianópolis, 88080-350, Santa Catarina, Brasil.

Email: elisaferrari@hotmail.com

Phone: (048) 33218600

Manuscript received on June 21, 2015

Manuscript accepted on January 01, 2016

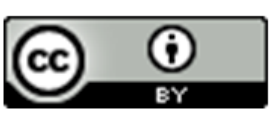

Motriz. The Journal of Physical Education. UNESP. Rio Claro, SP, Brazil - eISSN: 1980-6574 - under a license Creative Commons - Version 3.0 


\title{
ERRATUM
}

In the article "Athletic Identity Measurement Scale": Translation, Adaptation and Validation for Brazil, published in volume 22, number 1, 2016.

\author{
Kamyla Thais Dias de Freitas \\ Claudio Marcelo Tkac \\ Universidade do Estado de Santa Catarina, Florianópolis, SC, Brasil
}

Should read:

Kamyla Thais Dias de Freitas

Universidade do Estado de Santa Catarina, Florianópolis, SC, Brasil

Claudio Marcelo Tkac

Pontifícia Universidade Católica do Paraná, Curitiba, PR, Brasil

In the article "The effect of the maintaining the ball possession on the intensity of games", published in volume 22 , number 1, 2016.

René Brenzikofe

Should read:

René Brenzikofer

page 56, second column, lines 30-31:

"Ventilatory Threshold2" and "Ventilatory Threshold2 (VT2)" should read "VO2" 